\title{
Solubility Enhancement of Cox-II Inhibitors by Cosolvency Approach
}

\author{
P. R. Sathesh Babu' ${ }^{1}$, C. V. S. Subrahmanyam ${ }^{2}$, J. Thimmasetty ${ }^{1}$, \\ R. Manavalan ${ }^{3}$, K. Valliappan ${ }^{3}$ and S. A. Kedarnath ${ }^{4}$ \\ ${ }^{1}$ Bapuji Pharmacy College, Davangere-577 004, India \\ ${ }^{2}$ G.R. College of Pharmacy, Hyderabad-500 050, India \\ ${ }^{3}$ Department of Pharmacy, Annamalai University, Annamalainagar-608 001, India \\ ${ }^{4}$ SPI Pharma Inc., Bangalore-560100, India
}

\begin{abstract}
Solubility enhancement of meloxicam and rofecoxib, which are poorly soluble in water, was attempted. These are available in the form of solid dosage forms but not in solution dosage forms due to their low aqueous solubility. In this work, aqueous solubility of meloxicam and rofecoxib was improved using the biocompatible solvents such as ethanol, propylene glycol, glycerin, and PEG 400. Physico-chemical properties of the solvents such as intermolecular interactions and the ability of the solvent to form a hydrogen bond with the drug molecules were found to be the major factors involved in the dissolution of drugs. It was found that less polar solvents were found to increase solubility by greater extent, thus accentuating hydrophobic interaction mechanism. Among the solvent blends studied, water-PEG 400 had highest solubilization potential. Thus, the study generated an important dataset so as to compare effect of various cosolvents on the solubility of the drugs.
\end{abstract}

Key words: Aqueous solubility, Meloxicam, Rofecoxib, Cosolvency.

\section{INTRODUCTION}

Non-steroidal anti-inflammatory drugs (NSAIDs) are widely used for the long-term treatment of chronic rheumatic diseases such as rheumatoid arthritis, osteoarthritis, and ankylosing spondylitis. They have a broad spectrum effects and it has been suggested that the variations in both efficacy and tolerability of NSAIDs are partly due to differences in their physicochemical properties (e.g., solubility, partition coefficient, dielectric constant, and ionization constant) which determine their distribution in the body. ${ }^{1}$ When the aqueous solubility of a drug candidate is inadequate to permit solution formulations, cosolvents are often employed to improve solubility. ${ }^{2}$

\section{Correspondence to: P.R. Sathesh Babu}

E-mail: satish_puvvadi@rediffmail.com

Dhaka Univ. J. Pharm. Sci. 7(2): 119-126, 2008 (December)
Solubilization may be defined as the preparation of a thermodynamically stable solution of a substance that is normally insoluble or very slightly soluble in a given solvent, by the introduction of one or more amphiphilic component(s). ${ }^{3}$ Solubilization of poorly aqueous soluble drug forms an important activity in formulation process. Cosolvency, buffers, surfactants, and complexation are most commonly encountered pharmaceutical approaches for solubilizing drug(s) with low aqueous solubility. ${ }^{4}$ Use of cosolvent is one of the most popular approach in pharmaceutical liquid formulations. Modi and Tayade studied the effect of polyethylene glycol (PEG) on the enhancement of aqueous solubility of valdecoxib. ${ }^{5}$ Though highly effective, their use might be impeded by limit of cosolvent concentration that can be used and its precipitation on dilution. Use of cosolvent in combination with cyclodextrins, 
surfactants, and buffers have also been examined by other researchers. ${ }^{5-7}$

Meloxicam and rofecoxib are non-steroidal antiinflammatory drugs, which are active at a low dose and has less gastric toxicity. Meloxicam and rofecoxib exhibit anti-inflammatory and analgesic activity by selective inhibition of COX-II isoenzyme, which is responsible for the formation of prostaglandins in normal physiological conditions and no effect on COX-I isoenzyme at therapeutic concentrations.

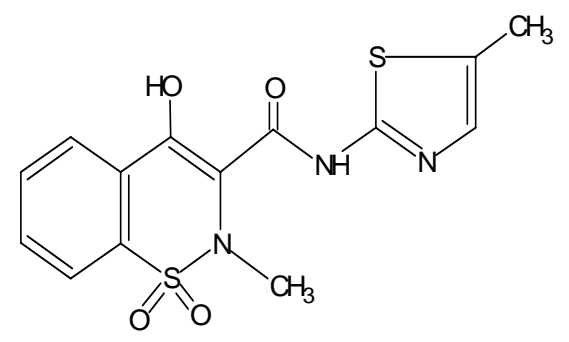

Structure of meloxicam

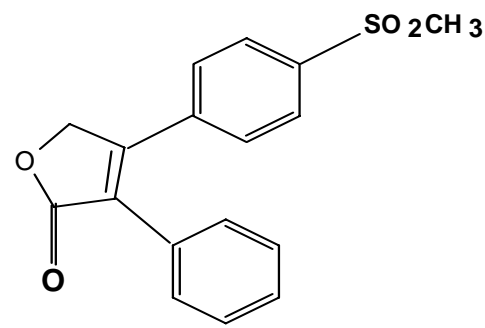

Structure of rofecoxib

According to biopharmaceutical classification system, rofecoxib and meloxicam are class II and class IV drugs, respectively. ${ }^{8,9}$ Since both are very poorly soluble, it is essential to improve their solubility using cosolvency technique. Although there have been enormous amount of research work performed using different techniques of solubilization, cosolvency technique needs to be explored. The aim of present study was to investigate effect of ethanol, propylene glycol (PG), glycerin, and PEG 400 on the aqueous solubility of the drugs.

\section{MATERIALS AND METHODS}

Rofecoxib and meloxicam were gift samples by Aarthi Drug Co. (Mumbai, India) and Dr. Reddy's lab (Hyderabad, India), respectively. Ethanol was purchased from Hayman Limited (England). All other chemicals and solvents used were of analytical grade.

Meloxicam and rofecoxib estimations were made in $0.1 \mathrm{~N}$ hydrochloric acid and $0.5 \mathrm{~N}$ sodium hydroxide solutions at $\lambda_{\max }$ of 345 and $351 \mathrm{~nm}$, respectively by UV method using spectrophotometer (1601 Shimadzu, Japan). Calibration curves obeyed Beer-Lambert's law in the concentration range of 2$14 \mu \mathrm{g} / \mathrm{ml}\left(\mathrm{R}^{2}=0.9996\right)$ and $5-40 \mu \mathrm{g} / \mathrm{ml}\left(\mathrm{R}^{2}=0.9985\right)$ for meloxicam and rofecoxib, respectively.

Cosolvency. Water and cosolvent were mixed volumetrically to form mixtures containing $0,10,20$, $30,40,50,60,70,80,90$, and $100 \%$ cosolvent in 50 $\mathrm{ml}$ stoppered volumetric flasks. Excess drug was added directly into the mixed solvents. The flasks were shaken in a cryostatic constant temperature reciprocating shaker bath (Research and test equipments, Bangalore, India) at room temperature $\left(25 \pm 1^{\circ} \mathrm{C}\right)$ for $24 \mathrm{~h}$ in order to obtain equilibrium, which was confirmed by comparing various samples at 24 and $48 \mathrm{~h}$. After $24 \mathrm{~h}$ of equilibrium, aliquots were withdrawn, filtered $(0.22 \mu \mathrm{m}$ pore size $)$ and diluted suitably. These samples were analyzed at 345 $\mathrm{nm}$ for meloxicam and $351 \mathrm{~nm}$ for rofecoxib using UV/Vis spectrophotometer (UV-1601 PC, Shimadzu, Japan). All solubility experiments were conducted in triplicate.

\section{RESULTS AND DISCUSSION}

Solubility in Pure Solvents. The solubility of meloxicam and rofecoxib in water and in some non aqueous solvents at $25^{\circ} \mathrm{C}$ is provided in Table 1 . Both the drugs exhibited poor water solubility. This is because the drugs, being predominantly nonpolar molecules, cannot effectively break into the lattice structure of water, hence water solubility is low. High values of experimentally determined octanolwater partition coefficients ( $\log p$ values of 
meloxicam and rofecoxib are 1.037 and 1.827, respectively) of drugs also suggest good solubility in lipophilic solvents. Solubility of meloxicam and rofecoxib was found to be particularly high in PEG 400 .

The solubility of meloxicam increased from $n$-propanol to $n$-octanol due to increased hydrophobic interaction as the alkyl chain length increases (Table 1). The solubility in lower members of alcohols (methanol and ethanol) was due to hydrogen bonding exhibited by meloxicam. The solubility of rofecoxib was high in lower member (methanol) and in higher members of series of alcohols (n-pentanol to n- octanol). These findings demonstrated two different types of interactions, viz., hydrogen bonding and hydrophobic interaction. The structure of rofecoxib also supported these assumptions. In methanol, rofecoxib predominately exhibited hydrogen bonding leading to high solubility. In the case of $n$-pentanol to $n$-octanol, the hydrophobic interaction predominated hydrogen bonding. In the middle members of series (ethanol, $n$-propanol, and $n$ butanol), the hydrophobic effects and hydrogen bonding were well balanced, leading to the rejection of rofecoxib molecules, thus squeezing of rofecoxib from the solvent bulk had resulted.

Table 1. Solubility of meloxicam and rofecoxib in different solvents at $25^{\circ} \mathrm{C}$

\begin{tabular}{lccccc}
\hline & & \multicolumn{2}{c}{ Solubility of meloxicam } & \multicolumn{2}{c}{ Solubility of Rofecoxib } \\
\cline { 3 - 6 } Solvent & Dielectric constant & $\mathrm{mg} / \mathrm{ml}$ & $\begin{array}{c}\text { molefraction } \\
\text { solubility }\end{array}$ & $\mathrm{mg} / \mathrm{ml}$ & $\begin{array}{c}\text { molefraction } \\
\text { solubility }\end{array}$ \\
\cline { 3 - 6 } Water & 78.36 & 0.1779 & $1.023 \mathrm{E}-05$ & 0.0004 & $2.350 \mathrm{E}-08$ \\
Glycerin & 42.50 & 0.0146 & $3.392 \mathrm{E}-06$ & 0.0203 & $4.700 \mathrm{E}-06$ \\
Methanol & 32.60 & 0.4376 & $5.638 \mathrm{E}-05$ & 0.3664 & $4.721 \mathrm{E}-05$ \\
Ethanol & 24.30 & 0.2454 & $4.582 \mathrm{E}-05$ & 0.0648 & $1.209 \mathrm{E}-05$ \\
Propanol & 20.10 & 0.2339 & $5.562 \mathrm{E}-05$ & 0.0337 & $8.012 \mathrm{E}-06$ \\
Butanol & 17.51 & 0.3024 & $8.803 \mathrm{E}-05$ & 0.0246 & $7.155 \mathrm{E}-06$ \\
Pentanol & 13.90 & 0.3167 & $1.090 \mathrm{E}-04$ & 0.1339 & $4.610 \mathrm{E}-05$ \\
Hexanol & 13.30 & 0.3487 & $1.385 \mathrm{E}-04$ & 0.3483 & $1.383 \mathrm{E}-04$ \\
Heptanol & - & 0.5037 & $2.263 \mathrm{E}-04$ & 0.3075 & $1.382 \mathrm{E}-04$ \\
Octanol & 10.34 & 0.6168 & $3.089 \mathrm{E}-04$ & 0.1981 & $9.921 \mathrm{E}-05$ \\
PG & 32.00 & 0.3489 & $8.150 \mathrm{E}-05$ & 0.0688 & $1.610 \mathrm{E}-05$ \\
PEG 300 & - & 6.3807 & - & 1.8440 & - \\
PEG 400 & 12.40 & 7.0014 & - & 1.0740 & - \\
\hline
\end{tabular}

Dielectric constant $(\varepsilon)$ of the solvents is collected from the literature and shown in Table 1. Table 1 shows that the solubility of the drugs decreases with an increase in the polarity of these solvents. Thus, polarity of the solvent is an important factor governing the solubility of the drugs. Hydrophobicity of the solvents also showed that the solubility increases with the hydrophobicity of the solvent. However polarity and hydrophobicity are not only the factors involved.

In the case of glycols, the increase in solubility is moving from PG to PEG 400 suggests that the hydrophobic interactions are more important in governing the solubility of the drugs in glycols. The exceptionally high solubility of drugs in PEG 400 is probably because of extensive hydrophobic interactions. With the solubility data obtained in the pure solvents, the enhancement of solubility was attempted using cosolvency approach, which is outlined in the further discussion.

Solubility in Mixed-Solvent Systems. Cosolvent addition is a highly effective technique for enhancement of solubility of poorly soluble drugs. Four commonly used cosolvents, ethanol, PG, glycerin, and PEG 400, were used in this study. The cosolvents are water miscible solvents, widely used 
in pharmaceutical field for solubilization purpose. The solvent with higher drug solubility (cosolvent) in the pure state is referred to as the stronger solvent and the other as the weaker solvent (water). The solubility $(\mathrm{mg} / \mathrm{ml}$ and molefraction solubility) values of meloxicam and rofecoxib in solvent blends at $25^{\circ} \mathrm{C}$ are given in Tables 2 to 5 for water and cosolvents (ethanol, PG, glycerin, and PEG 400, respectively).

Table 2. Solubility profiles of meloxicam and rofecoxib in water-ethanol mixtures of differing dielectric constants

\begin{tabular}{ccccccc}
\hline \multirow{2}{*}{$\begin{array}{c}\text { Water, } \\
(\%) \mathrm{v} / \mathrm{v}\end{array}$} & $\begin{array}{c}\text { Ethanol, } \\
(\%) \mathrm{v} / \mathrm{v}\end{array}$ & $\begin{array}{c}\text { Dielectric } \\
\text { constant }\end{array}$ & \multicolumn{2}{c}{ Solubility of meloxicam } & \multicolumn{2}{c}{ Solubility of Rofecoxib } \\
\cline { 4 - 7 } & & $\mathrm{mg} / \mathrm{ml}$ & $\begin{array}{c}\text { Molefraction } \\
\text { solubility }\end{array}$ & $\mathrm{mg} / \mathrm{ml}$ & $\begin{array}{c}\text { Molefraction } \\
\text { solubility }\end{array}$ \\
\hline 00 & 100 & 24.30 & 0.2454 & $4.58 \mathrm{E}-05$ & 0.0648 & $1.21 \mathrm{E}-05$ \\
10 & 90 & 29.71 & 0.3470 & $5.29 \mathrm{E}-05$ & 0.0920 & $1.40 \mathrm{E}-05$ \\
20 & 80 & 35.11 & 0.3599 & $4.64 \mathrm{E}-05$ & 0.0964 & $1.24 \mathrm{E}-05$ \\
30 & 70 & 40.52 & 0.3268 & $3.64 \mathrm{E}-05$ & 0.0741 & $8.26 \mathrm{E}-06$ \\
40 & 60 & 45.92 & 0.3176 & $3.12 \mathrm{E}-05$ & 0.0464 & $4.56 \mathrm{E}-06$ \\
50 & 50 & 51.33 & 0.2551 & $2.24 \mathrm{E}-05$ & 0.0308 & $2.70 \mathrm{E}-06$ \\
60 & 40 & 56.74 & 0.2652 & $2.11 \mathrm{E}-05$ & 0.0142 & $1.13 \mathrm{E}-06$ \\
70 & 30 & 62.14 & 0.2882 & $2.09 \mathrm{E}-05$ & 0.0042 & $3.05 \mathrm{E}-07$ \\
80 & 20 & 67.55 & 0.2542 & $1.70 \mathrm{E}-05$ & 0.0006 & $4.15 \mathrm{E}-08$ \\
90 & 10 & 72.95 & 0.2298 & $1.42 \mathrm{E}-05$ & 0.0002 & $1.15 \mathrm{E}-08$ \\
100 & 00 & 78.36 & 0.1779 & $1.02 \mathrm{E}-05$ & 0.0004 & $2.35 \mathrm{E}-08$ \\
\hline
\end{tabular}

Table 3. Solubility profiles of meloxicam and rofecoxib in water-PG mixtures of differing dielectric constants

\begin{tabular}{ccccccc}
\hline \multirow{2}{*}{$\begin{array}{c}\text { Water, } \\
(\%) \mathrm{v} / \mathrm{v}\end{array}$} & $\begin{array}{c}\mathrm{PG}, \\
(\%) \mathrm{v} / \mathrm{v}\end{array}$ & $\begin{array}{c}\text { Dielectric } \\
\text { constant }\end{array}$ & \multicolumn{2}{c}{ Solubility of meloxicam } & \multicolumn{2}{c}{ Solubility of Rofecoxib } \\
\cline { 4 - 7 } & & 32.00 & 0.3489 & $8.15 \mathrm{E}-05$ & 0.0688 & $1.61 \mathrm{E}-05$ \\
\hline 00 & 100 & 36.64 & 0.2509 & $4.49 \mathrm{E}-05$ & 0.0579 & $1.04 \mathrm{E}-05$ \\
10 & 90 & 41.27 & 0.2137 & $3.10 \mathrm{E}-05$ & 0.0527 & $7.64 \mathrm{E}-06$ \\
20 & 80 & 45.91 & 0.1806 & $2.20 \mathrm{E}-05$ & 0.0323 & $3.93 \mathrm{E}-06$ \\
30 & 70 & 50.54 & 0.1838 & $1.93 \mathrm{E}-05$ & 0.0148 & $1.55 \mathrm{E}-06$ \\
40 & 60 & 55.18 & 0.1843 & $1.70 \mathrm{E}-05$ & 0.0136 & $1.26 \mathrm{E}-06$ \\
50 & 50 & 59.82 & 0.1728 & $1.42 \mathrm{E}-05$ & 0.0068 & $5.63 \mathrm{E}-07$ \\
60 & 40 & 64.45 & 0.2027 & $1.51 \mathrm{E}-05$ & 0.0024 & $1.79 \mathrm{E}-07$ \\
70 & 30 & 69.09 & 0.2073 & $1.40 \mathrm{E}-05$ & 0.0007 & $4.67 \mathrm{E}-08$ \\
80 & 20 & 73.72 & 0.2004 & $1.25 \mathrm{E}-05$ & 0.0006 & $3.41 \mathrm{E}-08$ \\
90 & 10 & 78.36 & 0.1779 & $1.02 \mathrm{E}-05$ & 0.0004 & $2.35 \mathrm{E}-08$ \\
\hline
\end{tabular}

Table 4. Solubility profiles of meloxicam and rofecoxib in water-glycerin mixtures of differing dielectric constants

\begin{tabular}{ccccccc}
\hline \multirow{2}{*}{$\begin{array}{c}\text { Water, } \\
(\%) \mathrm{v} / \mathrm{v}\end{array}$} & $\begin{array}{c}\text { Glycerin } \\
(\%) \mathrm{v} / \mathrm{v}\end{array}$ & $\begin{array}{c}\text { Dielectric } \\
\text { constant }\end{array}$ & $\mathrm{mg} / \mathrm{ml}$ & $\begin{array}{c}\text { Solubility of meloxicam } \\
\text { molefraction } \\
\text { solubility }\end{array}$ & $\mathrm{mg} / \mathrm{ml}$ & molefraction solubility \\
\hline 00 & 100 & 42.50 & 0.0146 & $3.39 \mathrm{E}-06$ & 0.0203 & $4.7 \mathrm{E}-06$ \\
10 & 90 & 46.09 & 0.012 & $2.14 \mathrm{E}-06$ & 0.0149 & $2.65 \mathrm{E}-06$ \\
20 & 80 & 49.67 & $\mathrm{ND}$ & $\mathrm{ND}$ & 0.0122 & $1.76 \mathrm{E}-06$ \\
30 & 70 & 53.26 & 0.0195 & $2.37 \mathrm{E}-06$ & 0.0101 & $1.22 \mathrm{E}-06$ \\
40 & 60 & 56.84 & $\mathrm{ND}$ & $\mathrm{ND}$ & 0.0081 & $8.52 \mathrm{E}-07$ \\
50 & 50 & 60.43 & 0.0514 & $4.74 \mathrm{E}-06$ & 0.0059 & $5.4 \mathrm{E}-07$ \\
60 & 40 & 64.02 & $\mathrm{ND}$ & $\mathrm{ND}$ & 0.0042 & $3.5 \mathrm{E}-07$ \\
70 & 30 & 67.60 & 0.072 & $5.35 \mathrm{E}-06$ & 0.0029 & $2.15 \mathrm{E}-07$ \\
80 & 20 & 71.19 & $\mathrm{ND}$ & $\mathrm{ND}$ & 0.0012 & $8.04 \mathrm{E}-08$ \\
90 & 10 & 74.77 & 0.0668 & $4.16 \mathrm{E}-06$ & 0.0007 & $4.54 \mathrm{E}-08$ \\
100 & 00 & 78.36 & 0.1779 & $1.02 \mathrm{E}-05$ & 0.0004 & $2.35 \mathrm{E}-08$ \\
\hline $\mathrm{ND}=$ not determined
\end{tabular}


Table 5. Solubility profiles of meloxicam and rofecoxib in water-PEG 400 mixtures of differing dielectric constants

\begin{tabular}{ccccc}
\hline \multirow{2}{*}{$\begin{array}{c}\text { Water, } \\
(\%) \mathrm{v} / \mathrm{v}\end{array}$} & $\begin{array}{r}\text { PEG 400, } \\
(\%) \mathrm{v} / \mathrm{v}\end{array}$ & $\begin{array}{r}\text { Dielectric } \\
\text { constant }\end{array}$ & \multicolumn{2}{c}{ Mean Solubility $(\mathrm{mg} / \mathrm{ml}) \pm \mathrm{SD}$} \\
\cline { 4 - 5 } & 100 & 12.40 & $7.0014 \pm 0.3387$ & Rofecoxib \\
\hline 00 & 90 & 19.00 & $5.5577 \pm 0.3419$ & $1.0737 \pm 0.2977$ \\
10 & 80 & 25.59 & $3.6634 \pm 0.2168$ & $\mathrm{ND}$ \\
20 & 70 & 32.19 & $\mathrm{ND}$ & $0.3111 \pm 0.0620$ \\
30 & 60 & 38.78 & $0.9240 \pm 0.0503$ & $0.1278 \pm 0.0174$ \\
40 & 50 & 45.38 & $\mathrm{ND}$ & $0.0443 \pm 0.0062$ \\
50 & 40 & 51.98 & $0.0993 \pm 0.0049$ & $0.0192 \pm 0.0037$ \\
60 & 30 & 58.57 & $\mathrm{ND}$ & $\mathrm{ND}$ \\
70 & 20 & 65.17 & $\mathrm{ND}$ & $0.0034 \pm 0.0007$ \\
80 & 10 & 71.76 & $\mathrm{ND}$ & $0.0008 \pm 0.0003$ \\
90 & 00 & 78.36 & $0.1779 \pm 0.0132$ & $0.0004 \pm 0.0000$ \\
\hline
\end{tabular}

$\mathrm{ND}=$ not determined

Dielectric constants of the solvent mixtures were calculated from the relation $\varepsilon_{\text {mix }}=\varepsilon_{\mathrm{ws}} f_{\mathrm{ws}}+\varepsilon_{\mathrm{ss}} \mathrm{f}_{\mathrm{ss}}$, where $\varepsilon$ and $f$ are the dielectric constant and volume fraction, respectively; and subscripts mix, ws, and ss represent values for the mixture, weaker solvent, and stronger solvent, respectively. These values are also provided in Tables 2 to 5 . In most of the cases, solubility increased with a decrease in the dielectric constant of the mixture. Solubility decreased when the cosolvent, ethanol concentration was beyond $80 \%$ $\mathrm{v} / \mathrm{v}$ for both the drugs and in all the concentrations of glycerin-water blends for meloxicam. This effect occurs because drugs have some degree of polar character as well and maximum solubilization is a function of the relative polarity of the solute and the solvent. Moreover, factors other than the polarity of the solute and solvent are also involved.

Figure 1 shows solubility profile of meloxicam in water-cosolvent systems (ethanol, PG, glycerin, and PEG 400). All the cosolvents except glycerin showed exponential increase in solubility with increase in cosolvent fraction, where as glycerin showed decrease in solubility with increase in its concentration. The cosolvents formed a homogeneous mixture with water. This mixture had less polarity than pure water, as the cosolvents are less polar than water. ${ }^{10}$ The solubility of meloxicam increased because of the reduced polarity of the aqueous solution. However, meloxicam showed decreased solubility beyond $80 \% \mathrm{v} / \mathrm{v}$ water-ethanol mixtures. Water-PEG 400 combinations showed enormous increase in solubility when compared with other solvents blends. PEG 400, with a large non polar part and several hydroxyl groups is responsible for the enhanced solubility. Thus, among the four cosolvents used in this study, PEG 400 is the most effective and glycerin is the least effective in enhancing meloxicam solubility in water. However, glycerin decreased meloxicam solubility. The order of solubilizing power of the cosolvents is PEG $400>$ ethanol $>\mathrm{PG}>$ glycerin. The increment in solubility was found to be 2.02, 1.20, 0.08, and 20.59 fold for ethanol, PG, glycerin, and PEG 400 at $80 \%$ cosolvent level, respectively.

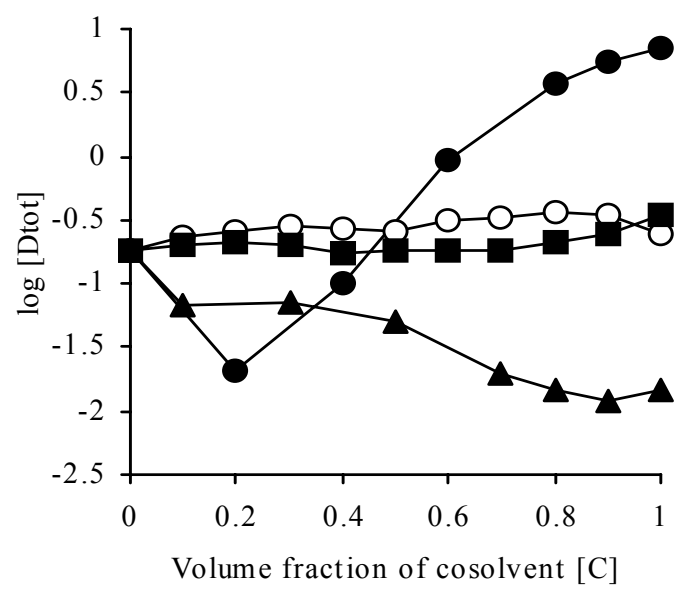

Figure 1. Comparative solubility profile of meloxicam in watercosolvent mixtures; Cosolvents used were ethanol (O), PG (ש), glycerin $(\boldsymbol{\Delta})$ and PEG $400(\bullet)$ 
The exponential dependence of the solubility of non polar solutes on cosolvent concentration in a semi aqueous solution is described as equation, ${ }^{11}$

$\log \left[\mathrm{D}_{\text {tot }}\right]=\log \left[\mathrm{D}_{\mathrm{u}}\right]+\sigma[\mathrm{C}]$

where $\left[D_{\text {tot }}\right]$ is the total apparent drug solubility, $\left[\mathrm{D}_{\mathrm{u}}\right]$ is the drug solubility in water, $[\mathrm{C}]$ is the cosolvent concentration, $\sigma$ is the cosolvent solubilizing power of the solute. The cosolvents usually reduce chemical potential of solution by decreasing hydrogen bond density of water, thus create a less polar environment in bulk, resulting in more drug molecules going into solution. Less polar the solvent, higher the solubilization power and higher the $\sigma$ value. As expected, PEG 400 being less polar showed better solubilization power. $\sigma$ values obtained from equation (1) for the various cosolvents are reported in Table 6. It is indicative that drug molecules preferably solubilize in non polar environment rather than polar (aqueous) surroundings. The $\sigma$ values were obtained from the equation (1) at [C] values higher than 0.10 .

Table 6. ' $\sigma$ ' values for various solvent-cosolvent systems

\begin{tabular}{|c|c|c|c|c|}
\hline \multicolumn{2}{|c|}{ Solvents blend } & \multirow[t]{2}{*}{$\begin{array}{l}\text { Concentration } \\
\text { range, }(\% \mathrm{v} / \mathrm{v})\end{array}$} & \multicolumn{2}{|c|}{$\begin{array}{c}\text { Stronger solvent } \\
\text { solubilization power } \\
\text { ' } \sigma \text { ' value }\end{array}$} \\
\hline $\begin{array}{l}\text { Solvent } \\
\text { (weaker } \\
\text { solvent) }\end{array}$ & $\begin{array}{c}\text { Cosolvent } \\
\text { (stronger } \\
\text { solvent) }\end{array}$ & & Meloxicam & Rofecoxib \\
\hline Water & PEG 400 & $20-100$ & 1.0917 & 3.6565 \\
\hline Water & Ethanol & $20-100$ & 0.4291 & 2.9256 \\
\hline Water & PG & $20-100$ & 0.1235 & 2.4902 \\
\hline Water & Glycerin & $20-100$ & -1.2288 & 2.1591 \\
\hline
\end{tabular}

Similar observations were made in case of rofecoxib. Figure 2 shows solubility profile of rofecoxib in water-cosolvent systems (ethanol, PG, glycerin, and PEG 400). All the cosolvents showed exponential increase in solubility with increase in cosolvent fraction. However, rofecoxib showed decreased solubility beyond $80 \% \mathrm{v} / \mathrm{v}$ water-ethanol mixtures similar to meloxicam. Water-PEG 400 combinations showed enormous increase in solubility of rofecoxib similar to meloxicam when compared with other solvents blends. Thus, among the four cosolvents used in this study, PEG 400 is the most effective and glycerin is the least effective. The order of solubilizing power of the cosolvents on the solubility of rofecoxib is PEG $400>$ ethanol $>$ PG > glycerin. The increment in solubility was found to be 241, 132, 31, and 778 fold for ethanol, PG, glycerin, and PEG 400, respectively at $80 \%$ cosolvent level.

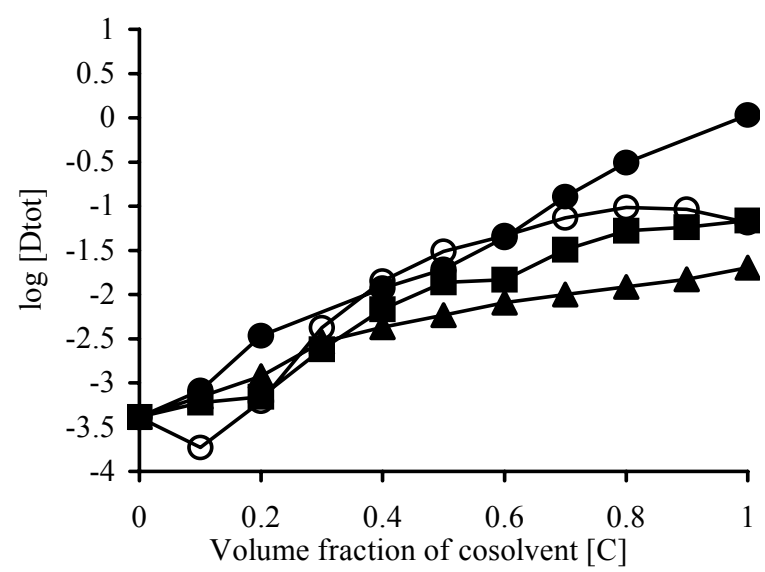

Figure 2. Comparative solubility profile of rofecoxib in watercosolvent mixtures; Cosolvents used were ethanol (O), PG (ם), glycerin ( $\mathbf{\Delta})$ and PEG $400(\bullet)$

Solubilizing power is dependent upon the molecular hydrophobic surface area of the solute and on the interfacial tension of the pure cosolvent against the drugs. In turn, the surface areas of the drugs are directly proportional to partition coefficients. Effect of partition coefficient on the solubility of meloxicam $(\log P=1.904)$ and rofecoxib ( $\log P=1.705$ ) in different solvent blends is shown in Figure 3. From the Figure 3, it infers that solubilizing power is directly proportional to logarithm of the drugs octanol/water partition coefficients. All the solubility curves for meloxicam lie above the solubility curves of rofecoxib, as the log $P$ of meloxicam is more than that of rofecoxib. This relationship is more convenient than that involving molecular surface area because of the ease with which partition coefficient is measured. ${ }^{13}$

The solubilities of meloxicam are expressed in $\mathrm{mg} / \mathrm{ml}$ and molefraction solubility in the Tables 1-5. Trends observed in $\mathrm{mg} / \mathrm{ml}$ and molefraction solubility are not similar unlike usually expected. It appears that solubilities in a series of solvents may vary according to which concentration units are 
chosen. Paruta has shown that the interpretation of solubility data depends greatly upon units chosen to express concentration. ${ }^{14}$ In the present case, there are two reasons why the molefraction data do not follow the same trend as the $\mathrm{mg} / \mathrm{ml}$ data. First, the molefraction solubility is dependent upon the $\mathrm{mg} / \mathrm{ml}$ concentration of the solute component and upon the molecular weights of both the solute and the solvent.

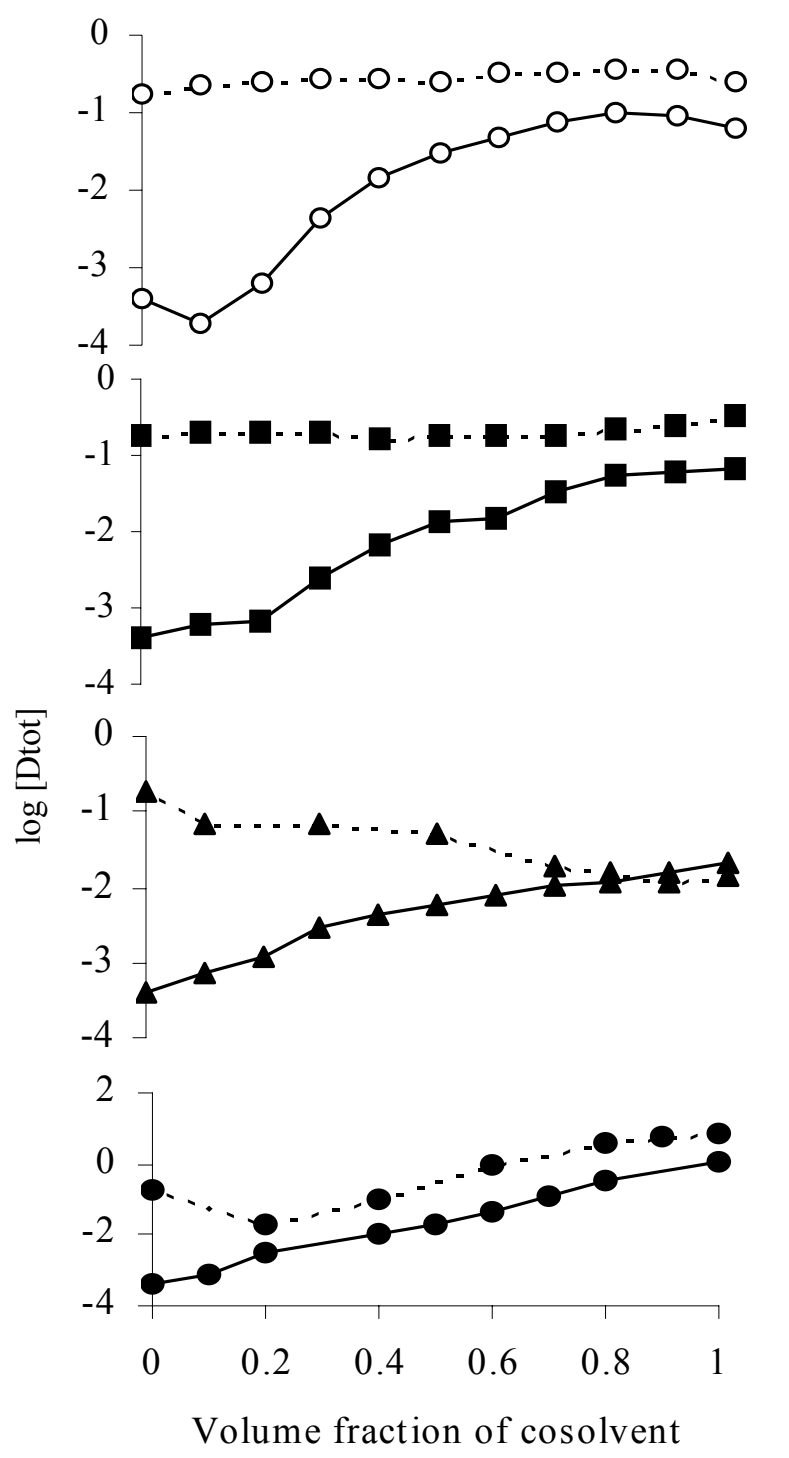

Figure 3. Effect of partition coefficient on the solubility of meloxicam (----), $\log P=1.904$ and rofecoxib ( $(-), \log P=$ 1.705 in different solvent blends; Cosolvents used were ethanol

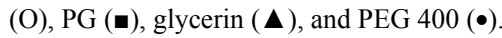

Second, when the solubilities of a particular solute are measured in a series of solvents, the molecular weight of a solute remains constant but molecular weights of the solvents vary. If the $\mathrm{mg} / \mathrm{ml}$ solubilities do not differ greatly from solvent to solvent, then the molecular weights of the solvents may assume unique importance in determining the molefraction solubility, even reversing the solubilities trend when certain conditions are met.

In case of rofecoxib also, the trends of $\mathrm{mg} / \mathrm{ml}$ and molefraction solubilities are not similar for water-ethanol system and alcohol series. The $\mathrm{mg} / \mathrm{ml}$ solubility of rofecoxib is highest in methanol when compared to all other alcohols, where as it's mole fraction solubility in methanol is equal to pentanol and is less than hexanol, heptanol, and octanol. The $\mathrm{mg} / \mathrm{ml}$ solubility of rofecoxib in pure ethanol is less than $70 \%$ of alcohol, where as it's mole fraction solubility is equal to that of $80 \%$ alcohol. Surprisingly, the trends are similar in water-PG and water-glycerin systems. This could be because of very low solubility in these systems where $\mathrm{mg} / \mathrm{ml}$ concentration and molecular weights of the solute and solvent will not predominate.

\section{CONCLUSION}

The degree of cosolvent effectiveness on the solubility of meloxicam and rofecoxib is not comparable. This may be the result of a conformational change in the structures of meloxicam and rofecoxib with solvent polarity i.e., the hydrogen bonds in the structures would be favored by nonpolar media but they are not likely to exist in strongly hydrogen bonding media such as water.

The study evaluated and compared solubility enhancement of meloxicam and rofecoxib using 4 different cosolvents. PEG 400 has been an acceptable cosolvent in terms of side-effect profile and also most efficient solubilizing cosolvent, improving solubility by nearly 21 fold at $80 \% \mathrm{v} / \mathrm{v}$ cosolvent level for meloxicam and 778 fold at $80 \%$ $\mathrm{v} / \mathrm{v}$ cosolvent level for rofecoxib. Thus the study 
generated an array of data for solubilization of meloxicam and rofecoxib using various pharmaceutically accepted cosolvents, which could be useful while formulating liquid dosage forms of meloxicam and rofecoxib.

\section{REFERENCES}

1. Luger, P., Daneck, K., Engel, W., Trummlitz, G. and Wagner, K. 1988. Structure and physicochemical properties of meloxicam, a new NSAID. Eur. J. Pharm. Sci. 4, 175-187.

2. Sweetana, S. and Akers, M.J. 1996. Solubility principles and practices for parenteral drug dosage form development. $J$. Pharm. Sci. Technol. 50, 330-342.

3. Atwood, D. and Florence, A.T. 1983. Surfactant systems. Chapman and Hall: London, p. 162.

4. Sathesh babu, P.R., Subrahmanyam, C.V.S., Thimmasetty, J., Manavalan, R. and Valliappan, K. 2007. Solubility of meloxicam in mixed solvent systems. Eth. Pharm. J. 25, 2328.

5. Modi, A. and Tayade, P. 2007. A comparative solubility enhancement profile of valdecoxib with different solubilization approaches. Ind. J. Pharm. Sci. 69, 274-278.

6. Li. P., Zaho, L. and Yalkowsky, S.H. 1999. Combined effect of cosolvent and cyclodextrins on solubilization of nonpolar drugs. J. Pharm. Sci. 88, 1107-1111.

7. Loftsson, T. Petersen, D.S. 1998. Cyclodextrin solubilization of ETH-615, a zwitterionic drug. Drug. Dev. Ind. Pharm. 24, 365-370.
8. Parya, R.N., Robert, R. and Piroska, S.R. 2006. Physicochemical characterization of meloxicam-mannitol binary systems. J. Pharm. Biomed. Ana. 41, 1191-1197.

9. Sanjula, B., Mona, D.and Kanchan, K. 2005. Physicochemical characterization, in vitro dissolution behavior, and pharmacodynamic studies of rofecoxibcyclodextrin inclusion compounds. Preparation and properties of rofecoxib hydroxypropyl b-cyclodextrin inclusion complex: a technical note. AAPS Pharm.Sci.Tech. 6, E83-90.

10. Ran, Y., Jain, A. and Yalkowsky, S.H. 2005. Solubilization and preformulation studies on PG-300995 (an anti-HIV drug). J. Pharm. Sci. 94, 297-303.

11. Yalkowsky, S.H, Flynn, G.L. and Amidon, G.L. 1972. Solubility of nonelectrolytes in polar solvents. J. Pharm. Sci. 61, 983-984.

12. Yalkowsky, S.H. and Rubino, J.T. 1985. Solubilization by cosolvents 1: Organic solutes in propylene glycol-water mixtures. J. Pharm. Sci. 74, 416-421.

13. Yalkowsky, S.H. 1981. In: Techniques of solubilization of drugs (Yalkowsky, S.H. and Roseman, T.J., Eds.), Marcel Dekker Inc., New York, p. 91.

14. John, W.M., Harold, P.J., Kenneth, S.A. and Anthony, N.P. 1977. Solubility of various sulphonamides in n-alkanols. I. Effect of polarity and temperature. Drug Dev. Ind. Pharm. 3, 163-183. 